\title{
Panorama del Orgware de la educación virtual en tiempo de COVID-19: Países de América Latina y el Caribe
}

\section{An Overview of the Orgware of Online Education in the Times of COVID-19 in Latin America and the Caribbean}

DOI: https://doi.org/10.32870/dse.v0i22.850

Nali Borrego Ramírez*

\begin{abstract}
Resumen
El estudio revisa los componentes del Orgware Virtual de la Educación (OVE) en América Latina y el Caribe durante los primeros meses de la pandemia de coronavirus (COVID-19). Está centrado en la competencia digital y el efecto en la virtualidad, el docente es el punto de partida. El enfoque metodológico de la teoría fundamentada permite derivar la estructura de conceptos relacionados con el fenómeno para convertirlos en variables. Igualmente, las dimensiones del modelo TPACK se convierten en procesos, para concluir que la sustantividad del OVE radica en la integración, aseguramiento e interacción permeadas por las condiciones pedagógicas, socioeconómica y tecnológicas. Los resultados revelan que la competencia digital de los docentes, en caso de poseerla, no es suficiente para llevar a cabo el proceso educativo de forma virtual, sino que se requiere la competencia pedagógica digital frente a una segunda crisis causada por el aumento del uso de Internet y la desigual tasa de conectividad en determinados segmentos poblacionales.
\end{abstract}

Palabras clave: Orgware - educación virtual - COVID-19 - competencia pedagógica digital.

\begin{abstract}
The study reviews the component environment of the Virtual Education Orgware (VEO) in Latin America and the Caribbean during the first months of the coronavirus disease pandemic (COVID-19). Focused on digital competence and the effect on virtuality, it views the teacher as the starting point. The grounded theory methodological approach allows this study to turn the structure of concepts related to the phenomenon into variables. Likewise, the dimensions of the TPACK model become processes, to conclude that the substantiveness of VEO lies in the integration, assurance and interaction permeated by pedagogical, socioeconomic and technological conditions. The results reveal that the digital competence of teachers, if they have it, is not enough to carry out the educational process virtually, but that digital pedagogical
\end{abstract}

* Doctora en investigación e innovación educativa. Miembro del cuerpo académico: Procesos Culturales y Metodológicos 107. Maestra de tiempo completo en la Unidad Académica Multidisciplinaria de Ciencias, Educación y Humanidades de la Universidad Autónoma de Tamaulipas. México.nali.borrego@gmail.com 
competence is required in the face of a second crisis caused by the increase in the use of the Internet and the unequal rate of connectivity for some segments of the population.

Keywords: Orgware - virtual education - COVID-19 - digital pedagogical competence.

\section{Introducción}

Los meses de marzo y abril de 2020 son inolvidables; fue cuando inició la cuarentena en los países de América Latina y el Caribe (ALyC), y con ella, las primeras experiencias relacionadas con el Covid-19, mientras que en otros países habían concluido o estaban por salir del proceso. Aunque las enfermedades infecciosas han acompañado la historia de la humanidad, este padecimiento se vincula estrechamente al factor social y económico. Las estrategias políticas no se hicieron esperar. Además de la Secretaría de Salud, como acción inicial se decidió que la primera institución en participar frente a la cuarenta fuera la educativa. De un día para otro cerraron sus puertas los centros educativos público y privados.

Los sistemas educativos se vieron en la necesidad de poner en operación la habilidad tecnológica de docentes y estudiantes, y los recursos disponibles para ello. De acuerdo con Borrego, Rodríguez, Walle, Ponce (2008), en términos prácticos significó la toma del sitio de contacto humano cara a cara, para construir realidad a partir de la información sensorial que pueden trasmitir las tecnologías de la comunicación, para situar a los sujetos en el aquí y el ahora, en el espacio y en el tiempo. Tales atributos se convierten en componentes estructurales del Orgware; Dobrov (1979) subraya que este tiene la misión de asegurar el funcionamiento y garantizar la interacción con otros elementos y con otros sistemas de naturaleza diferente.

Tanto el aseguramiento como la interacción de un sistema dedicado a la educación virtual se encuentra permeados por la evolución de la Brecha Digital (BD), que Lloyd (2020) caracteriza en tres etapas: las barreras, el uso, la participación de los sujetos en el contexto de las Tecnología de la Información y la Comunicación (TIC). Para algunos estudiosos, el uso de redes sociales representa el inicio de la competencia digital, sin embargo, no se encontró un registro preciso de su desempeño en la educación virtual vinculado con el uso de redes sociales. Es bien sabido que la conectividad es otro factor que influye en la brecha digital y, por consecuencia, en la eficacia de la educación virtual.

Para Lugo y Ithurburu (2019), las políticas educativas se han orientado al diseño e implementación de las políticas digitales educativas, sobre todo en las dimensiones: planeamiento y gestión, infraestructura y conectividad, cultura digital y la pedagógica. No obstante, los nuevos saberes requeridos confrontan al sistema educativo y al maestro, obligados a trabajar de forma virtual la unidad dicotómica TIC/gramática del Covid-19, contexto en el cual surgen preguntas en el interés por comprender lo que ocurre en la educación en tiempos de la pandemia. ¿Qué sucede en la escuela virtual en el momento actual, tras casi una década de políticas de in-

Diólo pos

sobre Educación año 12 | número 22 | enero-junio 2021 | ISSN 2007-2171 
tegración masiva de tecnologías? ¿Cómo han contribuido los desarrollos tecnológicos para continuar con el periodo escolar en la virtualidad? ¿Qué viven, especialmente, quienes se encuentran sin conexión a Internet fuera del contexto escolar? Los tres interrogantes pretenden aproximarse a la sustantividad del OVE en ALyC en tiempo de Covid-19. A continuación se plantea el proceso metodológico que se lleva a cabo.

\section{Método}

El desarrollo del estudio se apoya en estrategias metodológicas que, de acuerdo con Soneira (2006) y Charmaz (2013), proceden del enfoque de la teoría fundamentada en lo que se refiere al tratamiento de datos, codificación y análisis. Se parte de referentes teóricos previos para procesar la información.

El método investigativo utilizado es el propuesto por Neuman (2000) y Kumar (2011) (citados en Gutiérrez, 2015) para el análisis de contenido, que permite llevar a cabo el proceso de conversión de conceptos en variables debido a que admite cuantificar las variantes o cambios, o las veces que un fenómeno o evento ocurre. Se hace uso del método cuantitativo ya que un concepto no puede ser medido, mientras que una variable es susceptible de ser medida.

Se propone la conversión de conceptos relacionados con la enfermedad (COVID-19) a variables. Así como la conversión de las dimensiones del modelo TPACK en procesos. Las variables gramaticales de COVID-19 se identifican como los términos más buscados en Internet entre el 10 y el 25 de marzo, la palabra pandemia se ha buscado 48,817 veces, superando a cuarentena, buscada 38,791 veces; confinar, 24,168 veces y confinamiento, 19,166 veces (RAE, 2020). En cuanto al fundamento teórico-metodológico del modelo TPACK de Mishra y Koehler (2006), mismo que ha sido estudiado por otros investigadores.

\section{Desarrollo}

Fase 1. Conversión del concepto en variables:

Variable Externa: Orgware Virtual Educativo (VEOVE)

Cuadro 1. Conversión del concepto Orgware Virtual Educativo en variable

\begin{tabular}{|c|c|c|c|}
\hline \multirow[t]{2}{*}{ Concepto } & \multirow[t]{2}{*}{ Indicador } & \multicolumn{2}{|c|}{ Variables } \\
\hline & & Variable & Definición operacional \\
\hline $\begin{array}{c}\text { Orgware } \\
\text { Virtual Edu- } \\
\text { cativo }\end{array}$ & $\begin{array}{c}\text { Sistema } \\
\text { tecnológico }\end{array}$ & $\begin{array}{c}\text { Hombres. } \\
\text { Competencias profesionales. } \\
\text { Funcionamiento de hardware, } \\
\text { software y mindware. } \\
\text { Con sistemas diferentes. }\end{array}$ & $\begin{array}{l}\text { Integra, Asegura, } \\
\text { Interactúa. }\end{array}$ \\
\hline
\end{tabular}

Fuente: definición: Almenara (2004). 


\section{Variable Interna Pandemia (VIP)}

Cuadro 2. Conversión del concepto pandemia en variable

\begin{tabular}{|l|c|c|c|}
\hline Concepto & Indicador & \multicolumn{2}{|c|}{ Variables } \\
\cline { 3 - 4 } & & Variable & Definición operacional \\
\hline Pandemia & $\begin{array}{c}\text { Propagación } \\
\text { Enfermedad } \\
\text { infecciosa }\end{array}$ & $\begin{array}{c}\text { Extensión } \\
\text { geográfica }\end{array}$ & $\begin{array}{c}\text { Número de países o personas } \\
\text { afectadas }\end{array}$ \\
\hline
\end{tabular}

Fuente: definición: OMS (citada en Rosselli, 2020).

Es la primera variable interna verificada con el cierre de la mayor cantidad de centros educativos en todos los niveles durante los meses de marzo y abril de 2020, en 26 países de ALyC debido a la propagación de la enfermedad (COVID-19) (tabla 1).

Tabla 1. Alumnos afectados por cierre de escuelas en países de América Latina y el Caribe

\begin{tabular}{|c|c|c|c|c|c|}
\hline País & Preprimaria & Primaria & Secundaria & Terciaria & Total \\
\hline 1. Argentina & $\begin{array}{r}\text { M- 837,660 } \\
H-857,020 \\
\end{array}$ & $\begin{array}{r}2^{\prime} 331,295 \\
2^{\prime} 422,548\end{array}$ & $\begin{array}{r}2^{\prime} 298,226 \\
2^{\prime} 314,437\end{array}$ & $\begin{array}{l}1940,520 \\
1^{\prime} 200,443 \\
\end{array}$ & $\begin{array}{l}7^{\prime} 407,701 \\
6^{\prime} 794,448 \\
\end{array}$ \\
\hline Total & $1 ' 694,680$ & $4^{\prime} 753,843$ & $4^{\prime} 612,663$ & $3^{\prime} 140,963$ & $14^{\prime} 202,149$ \\
\hline 2. Bahamas & $M-1,813$ & 14,624 & 12,973 & - & 29,410 \\
\hline & $\mathrm{H}-1,781$ & 14,880 & 13,911 & - & 30,572 \\
\hline Total & 3,594 & 29,504 & 26,884 & - & 59,982 \\
\hline 3. Barbados & - & - & - & - & - \\
\hline 4. Belize & $\begin{array}{l}M-3,723 \\
H-3,626\end{array}$ & $\begin{array}{l}24,233 \\
26,531 \\
\end{array}$ & $\begin{array}{l}19,940 \\
20,413 \\
\end{array}$ & $\begin{array}{l}5,832 \\
3,593\end{array}$ & $\begin{array}{l}54,201 \\
53,690\end{array}$ \\
\hline Total & 7,349 & 50,764 & 40,353 & 9,425 & 107,891 \\
\hline 5. Bolivia & $\begin{array}{r}\text { M- } 174,480 \\
H-179,418 \\
\end{array}$ & $\begin{array}{l}671,302 \\
707,797 \\
\end{array}$ & $\begin{array}{r}635,904 \\
597,834 \\
\end{array}$ & - & $\begin{array}{l}1 ' 443,616 \\
1 ' 523,119\end{array}$ \\
\hline Total & 353,898 & 1'379,099 & $1^{\prime} 233,738$ & - & $2,966,735$ \\
\hline
\end{tabular}




\begin{tabular}{|c|c|c|c|c|c|}
\hline 6. Brasil & $\begin{array}{r}\text { M- 2'494,186 } \\
\text { H- 2'607,749 }\end{array}$ & $\begin{array}{l}7^{\prime} 716,415 \\
8^{\prime} 390,397 \\
\end{array}$ & $\begin{array}{l}11^{\prime} 620,916 \\
11^{\prime} 497,263 \\
\end{array}$ & $\begin{array}{r}4^{\prime} 871,95^{8} \\
3^{\prime} 699,465 \\
\end{array}$ & $\begin{array}{r}26^{\prime} 703,475 \\
26^{\prime} 194,874 \\
\end{array}$ \\
\hline Total & $5^{\prime} 101,935$ & $16^{\prime} 106,812$ & $23^{\prime} 118,179$ & $8^{\prime} 571,423$ & $52^{\prime} 898,349$ \\
\hline 7. Costa Rica & $\begin{array}{r}\text { M- 68,760 } \\
H-71,584 \\
\end{array}$ & $\begin{array}{r}237,354 \\
246,416 \\
\end{array}$ & $\begin{array}{l}235,076 \\
241,592 \\
\end{array}$ & $\begin{array}{l}116,600 \\
100,100 \\
\end{array}$ & $\begin{array}{l}657,790 \\
659,692 \\
\end{array}$ \\
\hline Total & 140,344 & 483,770 & 476,668 & 216,700 & 1'317,482 \\
\hline 8. Chile & $\begin{array}{r}\text { M- 299,914 } \\
\text { H- } 316,701 \\
\end{array}$ & $\begin{array}{l}733,094 \\
781,667 \\
\end{array}$ & $\begin{array}{r}771,917 \\
748,807 \\
\end{array}$ & $\begin{array}{l}652,294 \\
586,698 \\
\end{array}$ & $\begin{array}{l}2 ' 457,219 \\
2^{\prime} 433,873 \\
\end{array}$ \\
\hline Total & 616,615 & $1^{\prime} 514,761$ & 1'520,724 & 1'238,992 & 4'891,092 \\
\hline 9. Colombia & $\begin{array}{l}\text { M- 640,524 } \\
\text { H- } 668,862 \\
\end{array}$ & $\begin{array}{l}2^{\prime} 071,499 \\
2^{\prime} 232,334 \\
\end{array}$ & $\begin{array}{l}2 ' 399,891 \\
2 ' 421,138 \\
\end{array}$ & $\begin{array}{l}1^{\prime} 275,663 \\
1^{\prime} 132,378 \\
\end{array}$ & $\begin{array}{l}6,387,577 \\
6 ' 454,712 \\
\end{array}$ \\
\hline Total & 1'309,386 & $4^{\prime} 303,833$ & $4^{\prime} 821,029$ & $2^{\prime} 408,041$ & $12 ' 842,289$ \\
\hline 10. Ecuador & $\begin{array}{r}\text { M- } 230,656 \\
\mathrm{H}-317,895 \\
\end{array}$ & $\begin{array}{l}952,993 \\
979,268 \\
\end{array}$ & $\begin{array}{l}952,060 \\
939,588 \\
\end{array}$ & $\begin{array}{l}354,570 \\
314,867 \\
\end{array}$ & $\begin{array}{l}2^{\prime} 490,279 \\
2^{\prime} 551,618 \\
\end{array}$ \\
\hline Total & 548,551 & $1 ' 931,261$ & $1^{\prime} 891,648$ & 669,437 & $5^{\prime} 041,897$ \\
\hline 11. El Salvador & - & - & - & - & - \\
\hline 12. Guatemala & $\begin{array}{r}\text { M- } 297,495 \\
H-306,142 \\
\end{array}$ & $\begin{array}{l}1^{\prime} 140,181 \\
1^{\prime} 221,935\end{array}$ & $\begin{array}{r}640,180 \\
587,011 \\
\end{array}$ & $\begin{array}{l}196,430 \\
170,244 \\
\end{array}$ & $\begin{array}{l}2^{\prime} 274,286 \\
2^{\prime} 285,332\end{array}$ \\
\hline Total & 603,637 & $1^{\prime} 362,116$ & $1^{\prime} 227,191$ & 366,674 & 4'559,618 \\
\hline 13. Guyana & $\begin{array}{l}M-13,687 \\
H-14,185 \\
\end{array}$ & $\begin{array}{l}46,475 \\
48,013 \\
\end{array}$ & $\begin{array}{l}42,974 \\
42,960 \\
\end{array}$ & $\begin{array}{l}5,917 \\
2,940 \\
\end{array}$ & $\begin{array}{l}109,053 \\
108,098 \\
\end{array}$ \\
\hline Total & 27,872 & 54,488 & 85,934 & 8,857 & 271,151 \\
\hline 14. Haití & - & - & - & - & - \\
\hline 15. Honduras & $\begin{array}{r}M-120,874 \\
H-124,136 \\
\end{array}$ & $\begin{array}{l}550,353 \\
573,592 \\
\end{array}$ & $\begin{array}{l}311,454 \\
343,636 \\
\end{array}$ & $\begin{array}{l}151,819 \\
115,089 \\
\end{array}$ & $\begin{array}{l}1 ' 134,500 \\
1 ' 156,453 \\
\end{array}$ \\
\hline Total & 245,010 & 1'123,945 & 655,090 & 266,908 & 2'290,953 \\
\hline 16. Jamaica & - & - & - & - & - \\
\hline
\end{tabular}




\begin{tabular}{|c|c|c|c|c|c|}
\hline 17. México & $\begin{array}{l}\text { M- 2'447,884 } \\
H-2^{\prime} 494,639\end{array}$ & $\begin{array}{l}6^{\prime} 954,687 \\
7^{\prime} 227,601\end{array}$ & $\begin{array}{l}6^{\prime} 864,566 \\
7^{\prime} 169,986\end{array}$ & $\begin{array}{l}2^{\prime} 222,403 \\
2^{\prime} 207,854\end{array}$ & $\begin{array}{l}18^{\prime} 489,540 \\
19^{\prime} 100,080\end{array}$ \\
\hline Total & $4^{\prime} 942,523$ & $14^{\prime} 182,288$ & $14^{\prime} 034,552$ & 4'430,257 & $37^{\prime} 589,620$ \\
\hline 18. Nicaragua & - & - & - & - & - \\
\hline 19. Panamá & $\begin{array}{l}\text { M- 47,255 } \\
H-48,226\end{array}$ & $\begin{array}{l}202,660 \\
216,192 \\
\end{array}$ & $\begin{array}{l}159,982 \\
162,931 \\
\end{array}$ & $\begin{array}{l}97,350 \\
63,752 \\
\end{array}$ & $\begin{array}{l}507,247 \\
491,101 \\
\end{array}$ \\
\hline Total & 95,481 & 418,852 & 322,913 & 161,102 & 998,348 \\
\hline 20. Paraguay & $\begin{array}{r}\text { M- 89,035 } \\
\text { H- 91,972 }\end{array}$ & $\begin{array}{r}350,285 \\
377,078 \\
\end{array}$ & $\begin{array}{l}303,449 \\
307,859 \\
\end{array}$ & $\begin{array}{r}130,070 \\
95,141 \\
\end{array}$ & $\begin{array}{l}872,839 \\
872,050 \\
\end{array}$ \\
\hline Total & 181,007 & 727,363 & 611,308 & 225,211 & $1 ' 744,889$ \\
\hline 21. Perú & $\begin{array}{r}\text { M- 809,833 } \\
\text { H- 832,935 }\end{array}$ & $\begin{array}{l}1764,258 \\
1^{\prime} 828,607 \\
\end{array}$ & $\begin{array}{l}1^{\prime} 421,820 \\
1^{\prime} 358,153\end{array}$ & $\begin{array}{l}990,756 \\
905,151 \\
\end{array}$ & $\begin{array}{l}4^{\prime} 986,667 \\
4^{\prime} 924,846\end{array}$ \\
\hline Total & $1^{\prime} 642,768$ & $5^{\prime} 592,865$ & $2^{\prime} 779,973$ & $1 ' 895,907$ & $9 ' 911,513$ \\
\hline 22. Rep. Dom. & $\begin{array}{r}M-148,590 \\
H-150,559 \\
\end{array}$ & $\begin{array}{l}583,448 \\
642,966 \\
\end{array}$ & $\begin{array}{l}450,687 \\
474,027 \\
\end{array}$ & $\begin{array}{l}355,946 \\
200,577 \\
\end{array}$ & $\begin{array}{l}1 ' 538,671 \\
1 ' 468,129 \\
\end{array}$ \\
\hline Total & 199,149 & $1^{\prime} 226,412$ & 924,714 & 556,523 & 3'006,800 \\
\hline 23. Surinam & $\begin{array}{l}\text { M- 8,771 } \\
\text { H- 9,379 }\end{array}$ & $\begin{array}{l}32,584 \\
35,106 \\
\end{array}$ & $\begin{array}{l}30,292 \\
28,116 \\
\end{array}$ & $\begin{array}{l}3,213 \\
1,973 \\
\end{array}$ & $\begin{array}{l}74,860 \\
74,574 \\
\end{array}$ \\
\hline Total & 18,150 & 67,690 & 58,408 & 5,186 & 149,434 \\
\hline 24. Trin y Tob. & - & - & - & - & - \\
\hline 25. Uruguay & - & - & - & - & - \\
\hline 26. Venezuela & $\begin{array}{r}\text { M- 585,952 } \\
\text { H- } 604,397 \\
\end{array}$ & $\begin{array}{l}1586,206 \\
1^{\prime} 699,093\end{array}$ & $\begin{array}{l}1^{\prime} 174,444 \\
1^{\prime} 216,730\end{array}$ & $\begin{array}{l}1087,762 \\
1 ' 035,279\end{array}$ & $\begin{array}{l}4^{\prime} 434,364 \\
4^{\prime} 555,499 \\
\end{array}$ \\
\hline Total & 1'190,349 & $3^{\prime 285,299}$ & $2^{\prime} 391,174$ & 2'123,041 & $8 ' 989,863$ \\
\hline
\end{tabular}

Nota: De los países sin dato, no fue posible recuperlos.

Fuente: UNESCO (2020). 


\section{Variable Interna Cuarentena (VIC)}

Cuadro 3. Conversión del concepto cuarentena en variable

\begin{tabular}{|c|c|c|c|}
\hline Concepto & Indicador & \multicolumn{2}{|c|}{ Variables } \\
\cline { 3 - 4 } & & Variable & Definición operacional \\
\hline Cuarentena & Separación & $\begin{array}{c}\text { Personas expuestas } \\
\text { a enfermedad } \\
\text { contagiosa. }\end{array}$ & $\begin{array}{c}\text { Restricción de movimiento. } \\
\text { Impacto. }\end{array}$ \\
\hline
\end{tabular}

Fuente: definición: Brooks, Webster, Smith, Woodland, Wessely, Greenberg \& Rubin (2020).

La segunda variable interna es verificada con la restricción de movimiento a empresas, hogares, educación y todo tipo de organismo que requiere movimiento de personas, motivando la preocupación por el impacto (tabla 2).

Tabla 2. Porcentaje mínimo, máximo y media en opiniones por categoría en ALyC

\begin{tabular}{|l|c|r|r|}
\hline \multicolumn{1}{|c|}{ Categoría } & Mínimo de opiniones & Máximo de opiniones & \multicolumn{1}{c|}{ Media } \\
\hline 1. Seguridad sanitaria & $21.64 \%$ & $78.90 \%$ & $39.30 \%$ \\
2. Impacto Cultural & $2.94 \%$ & $25.39 \%$ & $10.82 \%$ \\
3. Economía empresas & $1.89 \%$ & $16.80 \%$ & $8.57 \%$ \\
4. Economía hogares & $1.39 \%$ & $15.98 \%$ & $10.49 \%$ \\
5. Medidas de Crisis & $0.86 \%$ & $11.76 \%$ & $4.09 \%$ \\
6. Seguridad alimentaria & $1.79 \%$ & $9.29 \%$ & $4.60 \%$ \\
7. Iniciativa ciudadana & $1.99 \%$ & $8.90 \%$ & $6.03 \%$ \\
8. Salud mental & $0.51 \%$ & $8.56 \%$ & $3.51 \%$ \\
9.Personas en vulnerabilidad & $0.34 \%$ & $8.17 \%$ & $2.58 \%$ \\
10. Educación & $1.05 \%$ & $5.92 \%$ & $2.73 \%$ \\
11. Noticias falsas & $0.69 \%$ & $4.65 \%$ & $2.25 \%$ \\
12.Teletrabajo & $0.78 \%$ & $4.47 \%$ & $2.94 \%$ \\
13.Medio Ambiente & $0.34 \%$ & $2.94 \%$ & $1.88 \%$ \\
\hline
\end{tabular}

Fuente: Observatorio COVID-19, BID (2020). Meses marzo y abril 2020.

La variable permite conocer que las opiniones recuperadas de Twiter ubican la educación como motivo de preocupación en décimo lugar, es decir, entre las categorías más bajas, solo antes de noticias falsas, el teletrabajo y el medio ambiente. Para corroborarlo, a continuación se presenta la cantidad de menciones para educación por país (tabla 3). 
Tabla 3. Comparativa de cantidad de menciones por país, para la educación

\begin{tabular}{|l|r|r|r|}
\hline \multicolumn{1}{|c|}{ País } & Menciones & Educación & Porcentaje \\
\hline 1. Argentina & 15,056 & 279 & $1.85 \%$ \\
\hline 2. Bahamas & 1,117 & 23 & $2.06 \%$ \\
\hline 3. Barbados & 503 & 17 & $3.38 \%$ \\
\hline 4. Belize & 176 & 6 & $3.41 \%$ \\
\hline 5. Bolivia & 2,594 & 69 & $2.73 \%$ \\
\hline 6. Brasil & 11,094 & 607 & $5.47 \%$ \\
\hline 7. Costa Rica & 3,508 & 104 & $2.96 \%$ \\
\hline 8. Chile & 1,695 & 99 & $5.84 \%$ \\
\hline 9. Colombia & 4,078 & 52 & $1.28 \%$ \\
\hline 10. Ecuador & 17,321 & 765 & $4.42 \%$ \\
\hline 11. El Salvador & 12,539 & 214 & $1.71 \%$ \\
\hline 12. Guatemala & 3,806 & 94 & $2.47 \%$ \\
\hline 13. Guyana & 517 & 19 & $3.68 \%$ \\
\hline 14. Haití & 756 & 13 & $1.72 \%$ \\
\hline 15. Honduras & 1,703 & 49 & $2.88 \%$ \\
\hline 16. Jamaica & 3,941 & 162 & $4.11 \%$ \\
\hline 17. México & 20,004 & 307 & $1.53 \%$ \\
\hline 18. Nicaragua & 1,407 & 39 & $2.77 \%$ \\
\hline 19. Panamá & 5,037 & 104 & $2.06 \%$ \\
\hline 20. Paraguay & 6,242 & 138 & $2.21 \%$ \\
\hline 21. Perú & 8,450 & 275 & $3.25 \%$ \\
\hline 22. Rep.Dom. & 7,659 & 119 & $1.55 \%$ \\
\hline 23. Surinam & 4,657 & 56 & $4.26 \%$ \\
\hline 24. Trin y Tob. & 5,137 & 89 & $3.38 \%$ \\
\hline 25. Uruguay & 6,470 & 171 & $3.33 \%$ \\
\hline 26.Venezuela & $1.38 \%$ \\
\hline
\end{tabular}

Fuente: Observatorio COVID-19, BID (2020).

La categoría que trata del impacto de la crisis sanitaria provocada por COVID-19 en la educación y alternativas didácticas durante el confinamiento, desde pequeña infancia hasta la universidad, se encuentra entre las categorías que obtienen los porcentajes bajos en cada uno de los países estudiados. 


\section{Variable Interna Confinamiento (VICO)}

Afirma Urresta (2017) que "confinamiento involucra una construcción social que de acuerdo al momento político, filosófico y social se ha ido direccionando para cumplir distintos objetivos".

Cuadro 4. Conversión del concepto confinamiento en variable

\begin{tabular}{|c|c|c|c|}
\hline Concepto & Indicador & \multicolumn{2}{|c|}{ Variables } \\
\cline { 3 - 4 } & & Variable & Definición operacional \\
\hline Confinamiento & Cierre & $\begin{array}{c}\text { Cantidad } \\
\text { de } \\
\text { establecimientos. }\end{array}$ & $\begin{array}{c}\text { Carácter del } \\
\text { desplazamiento. }\end{array}$ \\
\hline
\end{tabular}

Fuente: definición: González (2020).

Los establecimientos alcanzados por el cierre y considerados sin carácter de desplazamiento son aquellos destinados a la educación. Lo cual significa la afectación a la educación ya que sus servicios están asociados al índice de desigualdad.

\section{Variable Interna de VICO: Desigualdad (VICOD)}

Cuadro 5. Conversión del concepto desigualdad en variable

\begin{tabular}{|l|l|l|l|}
\hline Concepto & \multirow{2}{*}{ Indicador } & \multicolumn{2}{|c|}{ Variables } \\
\cline { 3 - 4 } & & Variable & Definición operacional \\
\hline Desigualdad & $\begin{array}{l}\text { Conexión } \\
\text { a internet }\end{array}$ & $\begin{array}{l}\text { Tecnologías } \\
\text { digitales. }\end{array}$ & $\begin{array}{l}\text { Trabajo. } \\
\text { Estudio. } \\
\text { Consumo. }\end{array}$ \\
\hline
\end{tabular}

Fuente: definición: CEPAL (2020).

A continuación se presentan los índices de desigualdad económica por país de ALyC (tabla 4).

Tabla 4. Comparativa de desigualdad por país

\begin{tabular}{|l|c|}
\hline \multicolumn{2}{|c|}{$\begin{array}{c}\text { Desigualdad en países de América } \\
\text { Latina Índice de Gini (de mayor } \\
\text { a menor) }\end{array}$} \\
\hline 1. Brasil & 51.3 \\
\hline 2. Colombia & 50.8 \\
\hline 3. Panamá & 50.4 \\
\hline 4. Honduras & 50.0 \\
\hline 5. Costa Rica & 48.7 \\
\hline 6. Guatemala & 48.3 \\
\hline
\end{tabular}




\begin{tabular}{|l|l|}
\hline 7. Paraguay & 47.8 \\
\hline 8. Chile & 47.7 \\
\hline 9. Nicaragua & 46.2 \\
\hline $\begin{array}{l}\text { 10. República } \\
\text { Dominicana }\end{array}$ & 45.3 \\
\hline 11. Ecuador & 45.0 \\
\hline 12. Bolivia & 44.6 \\
\hline 13. Perú & 43.8 \\
\hline 14. México & 43.4 \\
\hline 15. Argentina & 42.4 \\
\hline 16. Haití & 41.1 \\
\hline 17. El Salvador & 40.0 \\
\hline 18. Uruguay & 39.7 \\
\hline
\end{tabular}

Fuente: BM (2020), últimos datos disponibles para cada país.

De acuerdo con el coeficiente Gini, 0 representa una equidad perfecta, mientras que un índice de 100 representa una inequidad perfecta, según el Banco Mundial. El rasgo de desigualdad en América Latina agudiza la crisis socioeconómica motivada por el confinamiento (COVID-19).

El grado de desigualdad tiene que ver con la distribución del ingreso por día a nivel de país y regional (ver tabla 5).

Tabla 5. Clasificación de ingreso por día

\begin{tabular}{|c|c|}
\hline Condición & $\begin{array}{c}\text { Dólares por } \\
\text { día }\end{array}$ \\
\hline Pobreza & 1.9 \\
\hline Pobreza & 3.2 \\
\hline Pobreza & 5.5 \\
\hline Vulnerables & $5.5-13$ \\
\hline Clase media & $13-70$ \\
\hline Rico & $70-+$ \\
\hline
\end{tabular}

Fuente: BM (2020).

A las personas que se encuentran en condición de pobreza les corresponde el mayor porcentaje, seguido de aquellos en condición de vulnerabilidad. Estas poblaciones son las más afectadas en términos de educación por el cierre de centros educativos y el carácter del desplazamiento. 
La CEPAL (2020) revela la existencia de brechas en el acceso a las computadoras e Internet en los hogares, por lo que los procesos de enseñanza y aprendizaje a distancia no están garantizados debido a la disparidad de acceso a los dispositivos digitales e Internet de banda ancha entre las poblaciones urbanas y rurales; así como una desigualdad entre los sexos y entre las poblaciones que hablan o no el idioma oficial (español o portugués) y entre las poblaciones con y sin discapacidades. Como consecuencia, millones de niños y niñas de la región han dejado de recibir un desayuno, un refrigerio o un almuerzo en la escuela, por lo que la suspensión de clases tendrá un impacto no solo en la educación, sino también en la nutrición, en el cuidado, la participación de los padres, muy especialmente en las mujeres que se desempeñan en el mercado laboral. No podía ser de otra manera dada la situación de desigualdad.

La desigualdad está asociada con el acceso a Internet. A continuación se presenta el porcentaje de población de países de ALyC que usan Internet (tabla 6).

Tabla. 6. Uso de Internet, suscriptores de Facebook y estadísticas de población para las Américas

\begin{tabular}{|l|r|r|r|r|}
\hline Las Américas & $\begin{array}{r}\text { Población (2020 } \\
\text { Estudiada) }\end{array}$ & Uso de internet & $\begin{array}{c}\text { \% De población } \\
\text { (penetración) }\end{array}$ & \multicolumn{1}{|c|}{$\begin{array}{c}\text { Facebook 29- } \\
\text { feb-2020 }\end{array}$} \\
\hline Anguila & 14,909 & 12,557 & $84.2 \%$ & 9,000 \\
\hline $\begin{array}{l}\text { Antigua y Bar- } \\
\text { buda }\end{array}$ & 103,050 & 81,900 & $79.5 \%$ & 62,000 \\
\hline Argentina & $44^{\prime} 688,864$ & $41^{\prime} 586,960$ & $93.1 \%$ & $30^{\prime} 000,000$ \\
\hline Aruba & 105,670 & 100,000 & $94.6 \%$ & 91,000 \\
\hline Bahamas & 399,285 & 333,143 & $83.4 \%$ & 220,000 \\
\hline Barbados & 286,388 & 228,717 & $79.9 \%$ & 160,000 \\
\hline Belice & 382,444 & 200,020 & $52.3 \%$ & 200,000 \\
\hline Islas Bermudas & 61,349 & 60,122 & $98.0 \%$ & 39,000 \\
\hline Bolivia & $11^{\prime} 215,674$ & $8^{\prime} 817,749$ & $78.6 \%$ & $66^{\prime} 100,000$ \\
\hline $\begin{array}{l}\text { Bonaire, SE, } \\
\text { Saba }\end{array}$ & 25,398 & 20,956 & $82.5 \%$ & 15,000 \\
\hline Brasil & $210^{\prime} 867,954$ & $149^{\prime} 057,635$ & $70.7 \%$ & $139^{\prime} 000,000$ \\
\hline $\begin{array}{l}\text { Islas Vírgenes } \\
\text { Británicas }\end{array}$ & 31,196 & 14,620 & $46,9 \%$ & 12,000 \\
\hline Canadá & $36^{\prime} 953,765$ & $33^{\prime} 221,435$ & $89.9 \%$ & $23^{\prime} 000,000$ \\
\hline Islas Caimán & 61,559 & 54,630 & $88.7 \%$ & 48,000 \\
\hline Chile & $18^{\prime} 197,209$ & $14^{\prime} 108,392$ & $77.5 \%$ & $13^{\prime} 000,000$ \\
\hline Colombia & $49^{\prime} 464,683$ & $31^{\prime} 275,567$ & $63.2 \%$ & $29^{\prime} 000,000$ \\
\hline Costa Rica & $4,953,199$ & $41^{\prime} 296,443$ & $86.7 \%$ & $3^{\prime} 200,000$ \\
\hline Cuba & $4^{\prime} 630,000$ & $40.3 \%$ & $\mathrm{n} / \mathrm{a}$ \\
\hline
\end{tabular}




\begin{tabular}{|c|c|c|c|c|}
\hline Curazao & 161,577 & 151,274 & $93.6 \%$ & 120,000 \\
\hline Dominica & 73,925 & 49,687 & $67.2 \%$ & 39,000 \\
\hline $\begin{array}{l}\text { República Do- } \\
\text { minicana }\end{array}$ & $10^{\prime} 882,996$ & $6^{\prime} 649.904$ & $61.1 \%$ & $5,100,000$ \\
\hline Ecuador & $16^{\prime} 863,425$ & $13^{\prime} 476,687$ & $79.9 \%$ & $10^{\prime} 000,000$ \\
\hline El Salvador & $6^{\prime} 411,55^{8}$ & $3^{\prime} 700,000$ & $57.7 \%$ & $3^{\prime} 400,000$ \\
\hline Islas Malvinas & 2,922 & 2,900 & $99.2 \%$ & 3,100 \\
\hline $\begin{array}{l}\text { Guayana Fran- } \\
\text { cesa }\end{array}$ & 289,763 & 120,000 & $41.4 \%$ & 110,000 \\
\hline Groenlandia & 56,480 & 52,000 & $92.1 \%$ & 38,000 \\
\hline Granada & 108,339 & 69,245 & $63.9 \%$ & 62,000 \\
\hline Guadalupe & 449,173 & 240,000 & $53.4 \%$ & 220,000 \\
\hline Guatemala & $17^{\prime} 245,346$ & $7^{\prime} 268,597$ & $42.1 \%$ & $6,800,000$ \\
\hline Guayana & 782,225 & 395,007 & $50.5 \%$ & 360,000 \\
\hline Haití & $11^{\prime} 112,945$ & 2'000,000 & $18.0 \%$ & $1^{\prime} 800,000$ \\
\hline Honduras & $9^{\prime} 417,167$ & $3^{\prime} 600,000$ & $38.2 \%$ & $3^{\prime} 400,000$ \\
\hline Jamaica & $2^{\prime} 898,677$ & $1^{\prime} 581,100$ & $54.5 \%$ & $1^{\prime} 100,000$ \\
\hline Martinica & 385,065 & 303,302 & $78.8 \%$ & 170,000 \\
\hline México & $130^{\prime} 759,074$ & $85^{\prime} 000,000$ & $65.0 \%$ & $78^{\prime} 000,000$ \\
\hline Monserrat & 5,177 & 3,000 & $57.9 \%$ & 2,600 \\
\hline Nicaragua & $6^{\prime} 284.757$ & $2^{\prime} 700,000$ & $43.0 \%$ & $2^{\prime} 500,000$ \\
\hline Panamá & $4^{\prime} 162,618$ & $2^{\prime} 899,892$ & $69.7 \%$ & 2'000,000 \\
\hline Paraguay & $6^{\prime} 896,908$ & $6^{\prime} 177,748$ & $89.6 \%$ & $3,300,000$ \\
\hline Perú & $32^{\prime} 551,815$ & $22^{\prime} 000,000$ & $67.6 \%$ & $20^{\prime} 000,000$ \\
\hline Puerto Rico & $3^{\prime} 659,007$ & 3'047,311 & $83.3 \%$ & $2^{\prime} 100,000$ \\
\hline $\begin{array}{l}\text { San Bartolomé } \\
\text { (FR) }\end{array}$ & 7,184 & 7,240 & $100.8 \%$ & 6,400 \\
\hline $\begin{array}{l}\text { San Cristóbal y } \\
\text { Nieves }\end{array}$ & 55,345 & 43,618 & $78.8 \%$ & 35,000 \\
\hline Santa Lucía & 179,667 & 142,970 & $79.6 \%$ & 92,000 \\
\hline San Martín (FR) & 32,125 & 16,100 & $50.1 \%$ & 15,000 \\
\hline $\begin{array}{l}\text { San Pedro y } \\
\text { Maquelón }\end{array}$ & 6,320 & 5,033 & $79.6 \%$ & 3,100 \\
\hline $\begin{array}{l}\text { San Vicente y } \\
\text { Granadinas }\end{array}$ & 110,200 & 76,984 & $69.9 \%$ & 61,000 \\
\hline $\begin{array}{l}\text { Sint Maarten } \\
(\mathrm{NL})\end{array}$ & 40,120 & 33,000 & $82.3 \%$ & 31,000 \\
\hline Surinam & 568,301 & 340,000 & $59.8 \%$ & 310,000 \\
\hline
\end{tabular}




\begin{tabular}{|c|c|c|c|c|}
\hline $\begin{array}{l}\text { Trinidad y To- } \\
\text { bago }\end{array}$ & $1^{\prime} 372,598$ & $1^{\prime} 003,592$ & $73.1 \%$ & 700,000 \\
\hline Turcas y Caicos & 35,747 & 28,000 & $78.3 \%$ & 25,000 \\
\hline Estados Unidos & $326^{\prime} 766,748$ & $312 ' 322,257$ & $95.6 \%$ & $240^{\prime} 000,000$ \\
\hline Uruguay & $3^{\prime} 469,551$ & 3'059,727 & $88.2 \%$ & $2^{\prime} 400,000$ \\
\hline Islas Vírgenes & 104,914 & 63,529 & $60.6 \%$ & 22,000 \\
\hline Venezuela & $32^{\prime} 381,221$ & $17^{\prime} 178.743$ & $53.1 \%$ & $13^{\prime} 000,000$ \\
\hline Total & $1,015^{\prime} 892,65^{8}$ & $783^{\prime} 909,293$ & $77.2 \%$ & $641^{\prime} 481,200$ \\
\hline
\end{tabular}

Fuente: Internet World Itats (2020).

Rivoir (2019) asegura que numerosas personas con acceso a Internet lo hacen únicamente a través de celulares, sobre todo, esto ocurre en las zonas rurales. Se desconoce la gran cantidad de docentes, estudiantes y padres de familia que están dedicando las tecnologías digitales fundamentalmente al entretenimiento y la socialización por medio de las redes sociales como Facebook. En tanto, el provecho para la formación en un contexto educativo o para desarrollar habilidades útiles en la mejora académica de modo virtual, en el mejor de los casos pasa a segundo lugar; mientras tanto, la emergencia obliga a impulsar este pendiente. Las redes sociales más utilizadas en ALyC son You Tube, Facebook y WhatsApp dado que el contenido en español ocupa la cuarta posición en el mundo entero, representado por 20 países y más de 600 millones de habitantes, de los cuales destacan cuatro (tabla 7).

Tabla 7. Porcentaje de uso de redes sociales por país de ALyC

\begin{tabular}{|l|r|r|r|r|r|r|r|}
\hline País & Facebook & WhatsApp & FB Messenger & Twitter & You tube & Instagram & Móvil \\
\hline Argentina & $91 \%$ & $91 \%$ & $68 \%$ & & $93 \%$ & $68 \%$ & $69 \%$ \\
\hline México & $93 \%$ & $87 \%$ & $64 \%$ & $57 \%$ & & & $64 \%$ \\
\hline Chile & $82 \%$ & $78 \%$ & $46 \%$ & & $74 \%$ & $40 \%$ & $71 \%$ \\
\hline Colombia & $93 \%$ & $89 \%$ & $73 \%$ & & $96 \%$ & $73 \%$ & $62 \%$ \\
\hline
\end{tabular}

Fuente: Moreno (2019).

Entre los países con mayor actividad en redes sociales se encuentran: México, con $67 \%$ de un total de 131.5 millones de habitantes; Chile, con $77 \%$ de un total de 18.27 millones de habitantes; Colombia, 68\% de un total de 49.66 millones de personas; y Argentina, con 76\% de 44.90 millones de personas que habitan en el país (Moreno, 2019). La competencia digital desarrollada en las redes sociales no es suficiente para llevar a cabo la educación virtual, se requiere de la competencia digital pedagógica. 


\section{Fase 2. Conversión de las dimensiones del modelo TPACK en procesos para clasificar narrativas recuperadas de Twiter por el Observatorio COVID-19, BID (2020)}

Cuadro 6. Conversión de dimensión TPACK en proceso

\begin{tabular}{|c|c|c|c|}
\hline \multirow[t]{2}{*}{ Dimensión } & \multirow[t]{2}{*}{ Proceso } & \multicolumn{2}{|c|}{ Entradas-Salidas } \\
\hline & & Actividades & $\begin{array}{l}\text { Definición } \\
\text { operacional } \\
\end{array}$ \\
\hline $\begin{array}{l}\text { 1.TK.Competencias Tecnológicas } \\
\text { (Technological Knowledge) }\end{array}$ & $\begin{array}{l}\text { Manejo de } \\
\text { aplicaciones } \\
\text { tecnológicas. }\end{array}$ & $\begin{array}{l}\text { Usar, crear, } \\
\text { conectar. }\end{array}$ & $\begin{array}{l}\text { Organizar interre- } \\
\text { lacionar. }\end{array}$ \\
\hline $\begin{array}{l}\text { 2.PK.Competencias Pedagógicas } \\
\text { (Pedagogical Knowledge) }\end{array}$ & $\begin{array}{l}\text { Ejecución de } \\
\text { competencias } \\
\text { pedagógicas } \\
\text { en general. }\end{array}$ & & $\begin{array}{l}\text { Solucionar proble- } \\
\text { mas, } \\
\text { Evaluar competen- } \\
\text { cias. }\end{array}$ \\
\hline $\begin{array}{l}\text { 3.CK.Competencias Disciplinares } \\
\text { (Content Knowledge) }\end{array}$ & $\begin{array}{l}\text { Ejecución de } \\
\text { competencias } \\
\text { sobre la materia } \\
\text { en la que es ex- } \\
\text { perto. }\end{array}$ & & $\begin{array}{l}\text { Tomar decisiones } \\
\text { pertinentes. }\end{array}$ \\
\hline $\begin{array}{l}\text { 4.TPK.Competencias Tecnológi- } \\
\text { cas Pedagógicas } \\
\text { (Technological Pedagogical } \\
\text { Knowledge) }\end{array}$ & $\begin{array}{l}\text { Evaluar he- } \\
\text { rramientas } \\
\text { pedagógicas } \\
\text { así como herra- } \\
\text { mientas digita- } \\
\text { les. } \\
\end{array}$ & & $\begin{array}{l}\text { Practicar rutas mix- } \\
\text { tas. }\end{array}$ \\
\hline $\begin{array}{l}\text { 5.TCK.Competencias Tecnológi- } \\
\text { cas del Contenido. } \\
\text { (Technological Content Knowled- } \\
\text { ge) }\end{array}$ & $\begin{array}{l}\text { Aplica rutas } \\
\text { mixtas para } \\
\text { representar ma- } \\
\text { terias. }\end{array}$ & & $\begin{array}{l}\text { Evaluar conside- } \\
\text { rando el rendi- } \\
\text { miento de la ruta y } \\
\text { aprendizaje logra- } \\
\text { do. }\end{array}$ \\
\hline & & & \\
\hline
\end{tabular}




\begin{tabular}{|l|l|l|l|}
\hline $\begin{array}{l}\text { 6.PCK.Competencias Pedagógi- } \\
\text { cas del Contenido. } \\
\text { (Pedagogical Content Knowled- } \\
\text { ge) }\end{array}$ & $\begin{array}{l}\text { Conocer el tipo } \\
\text { de información, } \\
\text { el proceso men- } \\
\text { tal y el dominio } \\
\text { psicomotor } \\
\text { requeridos para } \\
\text { que el alum- } \\
\text { no adquiera } \\
\text { determinadas } \\
\text { habilidades o } \\
\text { contenidos. }\end{array}$ & & $\begin{array}{l}\text { Crear guías didác- } \\
\text { ticas. }\end{array}$ \\
\hline $\begin{array}{l}\text { 7.TPACK.Competencias Tecnoló- } \\
\text { gicas y } \\
\text { Pedagógicas del Contenido. } \\
\text { (Technological Pedagogical Con- } \\
\text { tent Knowledge) }\end{array}$ & $\begin{array}{l}\text { Identificar tec- } \\
\text { nología peda- } \\
\text { gógica en línea } \\
\text { para la imparti- } \\
\text { ción de determi- } \\
\text { nada materia. }\end{array}$ & & $\begin{array}{l}\text { Producir educación } \\
\text { virtual implicando } \\
\text { las competencias } \\
\text { TK, PK, CK, TPK, TCK, } \\
\text { PCK. }\end{array}$ \\
\hline
\end{tabular}

Fuente: Adaptación propia.

\section{Fase 3. Distribución de opiniones predominantes en twitter:}

1. El proceso TK. Conocimientos sobre capacidades y aplicaciones tecnológicas.

La responsabilidad de los docentes consiste en mantener contacto con los alumnos, mandarles trabajo, mantenerlos ocupados en trabajos productivos. Lo que significa acompañarlos mientras están en su casa.

Los opinantes creen que al menos los docentes saben lo que tienen que hacer, sin mencionar si saben cómo hacerlo. Es decir, conocen el proceso, mas no el procedimiento para lograr entradas y salidas.

En el desconocimiento del procedimiento y de cómo lograr entradas y salidas en modalidad virtual educativa por parte de los docentes inciden varios factores. García, Burgos, Murillo y Murillo (2019) encontraron que entre estos está una competencia digital deficiente, motivo por el cual un gran porcentaje de profesores tiene miedo al fracaso cuando utilizan tecnologías. Otro factor es el rechazo al uso de las tecnologías, debido a que nunca han recibido formación en competencia digital. Es frecuente que los docentes afirmen que es un conocimiento innecesario o que simplemente no les entra o que olvidan pronto. Melgar, Paredes-Labra y Reynes (2019) consideran que el verbo entrar, asociado con nuevos procedimiento, es determinante, por lo que el docente lo ve como un cuerpo extraño que violenta, del orden de la intromisión. Y un tercer factor que incide en el desarrollo de la competencia digital está asociado a un grupo etario de personas mayores, muy aislado de las tecnologías digitales (cuadro 7). 
Cuadro 7. Etapas del proceso de envejecimiento de la población en países ALyC

\begin{tabular}{|c|c|c|}
\hline Etapa & Descripción & Países \\
\hline $\begin{array}{l}\text { Envejecimiento } \\
\text { incipiente }\end{array}$ & $\begin{array}{l}\text { Países con niveles relativa- } \\
\text { mente altos de fecundidad } \\
\text { (más de } 3 \cdot 3 \text { hijos por mujer) y } \\
\text { un índice de envejecimiento } \\
\text { de menos de } 17 \text { personas ma- } \\
\text { yores por cada } 100 \text { menores } \\
\text { de } 15 \text { años. }\end{array}$ & $\begin{array}{l}\text { Belice, Bolivia, Guatemala, } \\
\text { Haití, Honduras, Nicara- } \\
\text { gua, Paraguay. }\end{array}$ \\
\hline $\begin{array}{l}\text { Envejecimiento } \\
\text { moderado }\end{array}$ & $\begin{array}{l}\text { Países con tasas de fecundi- } \\
\text { dad más bajas (entre } 2.3 \text { y } 3 \\
\text { hijos por mujer) e índices de } \\
\text { envejecimiento que oscilan } \\
\text { entre } 19.8 \text { y } 31.9 \text { personas } \\
\text { menores de } 15 \text { años. }\end{array}$ & $\begin{array}{l}\text { Bahamas, Brasil, Colom- } \\
\text { bia, Costa Rica, Ecuador, } \\
\text { El Salvador, Guyana, Ja- } \\
\text { maica, México, Panamá, } \\
\text { Perú, República Dominica- } \\
\text { na, Santa Lucía, Surinam, } \\
\text { Venezuela. }\end{array}$ \\
\hline $\begin{array}{l}\text { Envejecimiento } \\
\text { moderado a } \\
\text { avanzado }\end{array}$ & $\begin{array}{l}\text { Países con tasas de fecundi- } \\
\text { dad que varían entre } 1.7 \text { y } 2.5 \\
\text { hijos por mujer e índices de } \\
\text { envejecimiento que oscilan } \\
\text { entre } 32.8 \text { y } 51 \text { personas ma- } \\
\text { yores por cada } 100 \text { menores } \\
\text { de } 15 \text { años. }\end{array}$ & $\begin{array}{l}\text { Argentina, Chile, Trinidad } \\
\text { y Tabago }\end{array}$ \\
\hline $\begin{array}{l}\text { Envejecimiento } \\
\text { avanzado }\end{array}$ & $\begin{array}{l}\text { Países con menores niveles de } \\
\text { fecundidad (por debajo de la } \\
\text { tasa de reemplazo) e índices } \\
\text { de envejecimiento por enci- } \\
\text { ma de } 65 .\end{array}$ & Barbados, Cuba, Uruguay \\
\hline
\end{tabular}

Fuente: Sunkel y Ullmann (2019).

Sunkel y Ullmann (2019) y Lugo y Ithurburu (2019), refieren que las estadísticas de TIC disponibles para ALyC muestran al grupo etario de personas mayores muy aislado de las tecnologías digitales, lo que da cuenta de una profunda brecha digital. En la región, las personas mayores utilizan Internet menos que otros grupos etarios de la población. En consecuencia, la población con envejecimiento moderado o avanzado dedicada a la educación frente a grupos de estudiantes, tiene un desempeño que se traduce en moderado, toda vez que en el aula presencial cumplen con el proceso de aprendizaje. Sin embargo, para ellos el acceso a una computadora en el hogar no necesariamente significa la utilización de dicha herramienta y, por tanto, no participan activamente en las sociedades digitales en las que viven y el desempeño en educación virtual se les dificulta.

Elogia (2019) afirma que el factor género está presente como expresión de la competencia digital ya que la media de participación activa en el entorno social en ALyC es de $51 \%$ de muje- 
res y $49 \%$ de hombres. De acuerdo con la edad, el promedio del usuario de redes sociales está entre los 31 y 45 años; 39\% de los usuarios se sitúan en este rango. Después de este grupo se encuentran los jóvenes entre 16 y 30 años (31\%), seguidos muy de cerca del rango 46-65 años (30\%).

También el grado de estudios influye. La mayor parte de los activos en redes sociales (46\%) han completado estudios universitarios. Después se encuentran los que han completado la educación secundaria (40\%), seguidos de quienes tienen estudios posuniversitarios (10\%), y finalmente, quienes solo poseen educación primaria (3\%).

2. El proceso PK. El maestro posee competencias pedagógicas en general.

Se sugiere que estudiantes de medicina por graduarse, deben hacerlo cuanto antes para que apoyen en la pandemia.

En Paraguay 160 alumnos no reciben clases desde el 11 de marzo 2020.

Exigimos mejores condiciones para sobrellevar este duro momento desde el área educativa como alumnos.

El cierre de escuelas impacta en el aprendizaje.

La competencia pedagógica dinamiza grupos de alumnos en la solución de problemas. Los opinantes ponen sobre la mesa varias dificultades, sin conocer si los maestros o la institución están en posibilidad para resolverlas.

3. El procesos CK. Competencias sobre la materia en la que es experto. Se coteja con el número de Apps educativas descargadas anualmente por habitante. Se asume que la descarga de Apps educativas indica capacidad para continuar proveyendo educación a alumnos en el hogar (tabla 8).

Tabla 8. Uso de Internet para Apps educativas

\begin{tabular}{|l|r|}
\hline \multicolumn{1}{|c|}{ País } & \multicolumn{1}{c|}{ Porcentaje } \\
\hline 1. Argentina & 52.62 \\
\hline 2. Bolivia & 7.11 \\
\hline 3. Brasil & 65.22 \\
\hline 4. Chile & 87.35 \\
\hline 5. Colombia & 50.73 \\
\hline 6. Ecuador & 9.09 \\
\hline 7. El Salvador & 13.34 \\
\hline 8. Guatemala & 7.13 \\
\hline 9. Honduras & 10.83 \\
\hline
\end{tabular}




\begin{tabular}{|l|r|}
\hline 10. México & 48.19 \\
\hline 11. Panamá & 24.75 \\
\hline 12. Paraguay & 12.59 \\
\hline 13. Perú & 52.35 \\
\hline 14. Rep. Dom. & 16.89 \\
\hline
\end{tabular}

Nota: Ciertos países fueron excluidos de esta lista por falta de confiabilidad en los datos. Fuente: Observatorio CAF (2020).

El porcentaje de descargas se combina con los conocimientos pedagógicos y el conocimiento tecnológico de quien toma o imparte materias.

4. Los procesos TPK. Las competencias incluyen aspectos tecnológicos y pedagógicos; el 5. TCK. Conocimientos sobre cómo la tecnología puede utilizarse para representar la materia a utilizar y desarrollar la competencia disciplinar; el 6. PCK. Conocimientos pedagógicos que faciliten a los alumnos adquirir determinadas habilidades o contenidos. Son tres procesos enlazados directamente en la producción de proyectos tecnológicos. A continuación, algunas opiniones relacionadas.

En medio de crisis económica se dice que alumnos que no cumplan con los pagos, son retirados automáticamente de la plataforma virtual, único medio de clases en este tiempo.

Todos los estudiantes universitarios privados deben luchar por sus derechos, en tiempos de pandemia donde la universidad no gasta en agua, luz y mantenimiento, se beneficia en medio de la crisis por la que todos están pasando.

En México, se implementa un curso de lengua de señas para hacer frente a la crisis. Pero también se habla del uso político para romper un movimiento válido con el regreso a clases online. Así como tapar la lucha contra la violencia de género y forzar a los alumnos a darse de baja si no están de acuerdo es lamentable.

Más allá de las competencias en aspectos tecnológicos y pedagógicos para impartir una materia, los opinantes detectan que a la educación virtual le acompañan otros inconvenientes.

Sin embargo, se requiere de la institución y el que prueben varias tecnologías y después elijan aquella que contribuya a comunicarse con alumnos en casa. Para dar una respuesta a procesos enlazados se recurre al inventario de proyectos de apoyo a la educación virtual, dirigido por Delgado (2020), y disponible durante la pandemia en ALyC, entre los cuales destacan elementos pedagógicos contenidos en el proyecto y la cantidad de alumnos que se supone deben hacer uso de cada uno de dichos proyectos. En el cuadro 8 se enuncian los proyectos por país, su objetivo y la liga para su localización en Internet.

Cuadro 8. Proyectos para la educación de educación virtual en países de ALyC 


\begin{tabular}{|c|c|}
\hline Proyecto & URL \\
\hline $\begin{array}{l}\text { 1. Argentina } \\
\text { Programa Seguimos Educando. } \\
\text { Objetivo: } \\
\text { Que los niños, niñas, adolescentes y universitarios pue- } \\
\text { dan continuar con la educación en sus hogares. }\end{array}$ & $\begin{array}{l}\text { https://www.educ.ar/noti- } \\
\text { cias/200376/la-clase-del-diacu- } \\
\text { tea-ideas-para-articular-las-pro- } \\
\text { puestas-de-seguimos-educando }\end{array}$ \\
\hline $\begin{array}{l}\text { 2. Bolivia } \\
\text { Grupo de Educadores Google Bolivia. } \\
\text { Objetivo: } \\
\text { Apoyará al fortalecimiento de la Educación Virtual y } \\
\text { a Distancia que viene emprendiendo el Ministerio de } \\
\text { Educación como alternativa y apoyo a la educación } \\
\text { presencial establecida en todo el territorio nacional. }\end{array}$ & $\begin{array}{l}\text { https://www.minedu.gob.bo/ } \\
\text { index.php?option=com_cont } \\
\text { ent\&view=article\&id=4549:go } \\
\text { ogle-for-education-capacita- } \\
\text { a-educadores-para-el-uso-de- } \\
\text { plataformas-y-herramientas-de- } \\
\text { educacion-virtual\&catid=182:- } \\
\text { noticias\&Itemid=854 }\end{array}$ \\
\hline $\begin{array}{l}\text { 3. Brasil } \\
\text { Hasta el momento no ha desarrollado un plan de edu- } \\
\text { cación en casa. }\end{array}$ & $\begin{array}{l}\text { https://blogs.worldbank.org/es/ } \\
\text { education/Gestionar-el-impacto- } \\
\text { de-la-COVID-19-en-los-sistemas- } \\
\text { educativos }\end{array}$ \\
\hline $\begin{array}{l}\text { 4. Colombia } \\
\text { Plan Aprender Digital, Contenidos para Todos - Para la } \\
\text { educación primaria y secundaria Plan de Auxilios Edu- } \\
\text { cativos para beneficiarios de ICETEX (Instituto Colom- } \\
\text { biano de Crédito Educativo y Estudios Técnicos en el } \\
\text { Exterior) - Para la educación superior. } \\
\text { Objetivo: } \\
\text { Ofrecer contenidos educativos innovadores y de cali- } \\
\text { dad para niños, niñas, adolescentes y jóvenes para to- } \\
\text { dos los niveles educativos en diversos formatos. }\end{array}$ & $\begin{array}{l}\text { https://www.mineducacion.gov. } \\
\text { co/1759/articles-393910_recur- } \\
\text { so_1.pdf } \\
\text { https://www.mineducacion. } \\
\text { gov.co/1759/w3-article-394449. } \\
\text { html?_noredirect=1 }\end{array}$ \\
\hline $\begin{array}{l}\text { 5. Costa Rica } \\
\text { Plan de Orientaciones para la intervención educativa en } \\
\text { centros educativos ante el COVID-19 } \\
\text { Objetivo: } \\
\text { Ofrecer orientaciones al personal técnico-docente y } \\
\text { docentes, así como a la comunidad educativa en gene- } \\
\text { ral, para realizar una adecuada intervención educativa } \\
\text { en el centro, que contribuya a la prevención, postergue } \\
\text { el contagio del virus, pero sobre todo que beneficie la } \\
\text { continuidad del proceso educativo de las personas es- } \\
\text { tudiantes. }\end{array}$ & $\begin{array}{l}\text { https://www.mep.go.cr/sites/ } \\
\text { default/files/page/adjuntos/ } \\
\text { orientaciones-intervencion- } \\
\text { educativa.pdf }\end{array}$ \\
\hline $\begin{array}{l}\text { 6. Cuba } \\
\text { Programación televisiva Teleclase } \\
\text { Objetivo: } \\
\text { Metodólogos y teleprofesores en el horario estableci- } \\
\text { do, orienten por niveles educativos, grados y asigna- } \\
\text { turas, a los estudiantes en los objetivos y contenidos } \\
\text { previstos a vencer en la etapa, con la utilización de los } \\
\text { materiales escolares que cuentan. }\end{array}$ & $\begin{array}{l}\text { https://www.mined.gob.cu/ } \\
\text { adopta-ministerio-de-educa- } \\
\text { cion-nuevas-medidas-ante-la- } \\
\text { covid-19/ }\end{array}$ \\
\hline
\end{tabular}




\begin{tabular}{|c|c|}
\hline $\begin{array}{l}\text { 7. Chile } \\
\text { Plan Aprendo en Casa } \\
\text { Objetivo: } \\
\text { Llegar a cada rincón de Chile con las herramientas pe- } \\
\text { dagógicas necesarias. }\end{array}$ & $\begin{array}{l}\text { https://es.unesco.org/fieldoffice/ } \\
\text { santiago/articles/ministro-edu- } \\
\text { cacion-Chile-covid-19 }\end{array}$ \\
\hline $\begin{array}{l}\text { 8. Ecuador } \\
\text { Plan Educativo Aprendamos Juntos en Casa } \\
\text { Objetivo: } \\
\text { Lograr que los estudiantes continúen con sus activida- } \\
\text { des académicas desde sus hogares, mediante varias } \\
\text { acciones didácticas en las que los docentes deben tra- } \\
\text { bajar en forma conjunta con los coordinadores de áreas } \\
\text { para elaborar guías de aplicación de los recursos educa- } \\
\text { tivos. Mientras que, los departamentos especializados } \\
\text { realicen apoyo psicoemocional y pedagógico. }\end{array}$ & https://educacion.gob.ec/ \\
\hline $\begin{array}{l}\text { 9. El Salvador } \\
\text { Plan de Continuidad Educativa } \\
\text { Objetivo: } \\
\text { Orientar los procesos de aprendizaje desde casa. }\end{array}$ & $\begin{array}{l}\text { https://www.mined.gob.sv/ } \\
\text { emergenciacovid19/ }\end{array}$ \\
\hline $\begin{array}{l}\text { 10. Guatemala } \\
\text { Programa Aprendo en Casa CovID-19 (También en edu- } \\
\text { cación Extraescolar) } \\
\text { Objetivo: } \\
\text { La Secretaría de Educación ha estado impulsando des- } \\
\text { de varias estrategias, la actividad educativa en los dife- } \\
\text { rentes niveles del sistema. }\end{array}$ & $\begin{array}{l}\text { https://criterio.hn/wp-content/ } \\
\text { uploads/2020/O4/OUDENI- } \\
\text { Informe-Sistema-Educativo- } \\
\text { en-el-contexto-del-COVID-19_- } \\
\text { abril-2020_vf-1.pdf }\end{array}$ \\
\hline $\begin{array}{l}\text { 11. Honduras } \\
\text { ND: } \\
\text { Objetivo: } \\
\text { La Secretaría de Educación ha estado impulsando } \\
\text { desde varias estrategias, la actividad educativa en los } \\
\text { diferentes niveles del sistema. Se está trabajando con } \\
\text { videos, clases en línea, televisión educativa, proporcio- } \\
\text { nando indicaciones al personal docente sobre el desa- } \\
\text { rrollo de contenidos por medio de guías, pero también } \\
\text { respecto al cuidado de la salud socioemocional de los } \\
\text { educandos. }\end{array}$ & $\begin{array}{l}\text { https://criterio.hn/wp-content/ } \\
\text { uploads/2020/o4/OUDENI- } \\
\text { Informe-Sistema-Educativo- } \\
\text { en-el-contexto-del-COVID-19_- } \\
\text { abril-2020_vf-1.pdf }\end{array}$ \\
\hline $\begin{array}{l}\text { 12. México } \\
\text { Plan Aprende en Casa (COVID-19) } \\
\text { Objetivo: } \\
\text { Asegurar el bienestar de la comunidad educativa ante } \\
\text { la presencia de infecciones respiratorias en el Sistema } \\
\text { Nacional de Educación. }\end{array}$ & $\begin{array}{l}\text { https://www.telesurtv.net/ } \\
\text { news/mexico-programa-virtual- } \\
\text { educacion-aprende-casa-co- } \\
\text { vid-20200420-0061.htmll }\end{array}$ \\
\hline $\begin{array}{l}\text { 13. Nicaragua } \\
\text { No está aplicando ningún plan educativo específico. }\end{array}$ & $\begin{array}{l}\text { https://www.ellitoral.com/index. } \\
\text { php/id }\end{array}$ \\
\hline
\end{tabular}




\begin{tabular}{|c|c|}
\hline $\begin{array}{l}\text { 14. Panamá } \\
\text { Plan Modalidad de Enseñanza por Región y Cultura } \\
\text { Educativa. } \\
\text { Objetivo: } \\
\text { Reconvertir y reinventar el sistema de educación, en- } \\
\text { focado en los ejes de equidad y calidad, y tomando en } \\
\text { cuenta la desigualdad entre las regiones educativas. }\end{array}$ & $\begin{array}{l}\text { https://www.prensa.com/impre- } \\
\text { sa/panorama/copeme-entrego- } \\
\text { almeduca- un-plan-educativo- } \\
\text { ante-la-pandemia/ }\end{array}$ \\
\hline $\begin{array}{l}\text { 15. Paraguay } \\
\text { Tu Escuela en Casa } \\
\text { Objetivo: } \\
\text { Es un soporte hasta que la educación paraguaya re- } \\
\text { tome la actividad normal, es un medio de contención } \\
\text { para la familia educativa mientras dure la medida pre- } \\
\text { ventiva. }\end{array}$ & $\begin{array}{l}\text { https://aprendizaje.mec.edu.py/ } \\
\text { aprendizaje/ }\end{array}$ \\
\hline $\begin{array}{l}\text { 16. Perú } \\
\text { Programas educativos de TV y radio en Perú: horarios } \\
\text { de (Aprendo en Casa) } \\
\text { Objetivo: } \\
\text { Aplicar el programa, diseñado para educación inicial, } \\
\text { primaria, secundaria y básica especial, para no inte- } \\
\text { rrumpir el año escolar en pleno estado de emergencia } \\
\text { por la expansión del coronavirus en el Perú. }\end{array}$ & $\begin{array}{l}\text { https://cdn.www.gob.pe/ } \\
\text { uploads/document/file/565531/ } \\
\text { RVM_N__o79-2020-MINEDU.PDF } \\
\text { https://resources.aprendoenca- } \\
\text { sa.pe/perueduca/radio-and-tv/ } \\
\text { programacion.pdf }\end{array}$ \\
\hline $\begin{array}{l}\text { 17. República Dominicana } \\
\text { Plan Apoyo Educativo. } \\
\text { Objetivo: } \\
\text { Dar respuesta pedagógica ante la suspensión temporal } \\
\text { de las actividades de los centros educativos a nivel na- } \\
\text { cional. }\end{array}$ & $\begin{array}{l}\text { http://www.educa.org. } \\
\text { do/2020/o4/13/consideracio- } \\
\text { nes-sobre-los-efectos-de-la- } \\
\text { covid-19-en-el-calendario-esco- } \\
\text { lar-2019-2020/ }\end{array}$ \\
\hline $\begin{array}{l}\text { 18. Uruguay } \\
\text { Plan Ceibal } \\
\text { Objetivo: } \\
\text { Poner a disposición de su público beneficiario recursos } \\
\text { para docentes y estudiantes, así como programas a dis- } \\
\text { tancia para ayudar a mitigar los efectos de la suspen- } \\
\text { sión de las actividades educativas por cierre temporal } \\
\text { de los centros educativos a causa de la llegada del virus } \\
\text { causante de CoVID-19 al país. }\end{array}$ & $\begin{array}{l}\text { https://www.ceibal.edu.uy/es/ } \\
\text { articulo/recursos-de-plan-ceibal- } \\
\text { ante-Ilegada-de-coronavirus- } \\
\text { uruguay }\end{array}$ \\
\hline $\begin{array}{l}\text { 19. Venezuela } \\
\text { Plan Cada Familia una Escuela. } \\
\text { Objetivo: } \\
\text { Según una orientación pedagógica, basada en cuatro } \\
\text { ejes: - Creación de videos informativos y difundirlo a } \\
\text { través del WhathApp. - Creación de una programación } \\
\text { educativa en TV. - Creación de portafolio direccionado } \\
\text { a evaluar a los estudiantes. - Creación de guías del do- } \\
\text { cente que se repartirán a sectores más alejados. }\end{array}$ & $\begin{array}{l}\text { https://reliefweb.int/report/ } \\
\text { venezuela-bolivarian-republic/ } \\
\text { venezuela-alternativas-para-la- } \\
\text { continuidad-educativa-ante-el }\end{array}$ \\
\hline
\end{tabular}

Fuente: Delgado y Grupo de Maestría en Educación (2020). 
En 19 países se constata la existencia de competencias que permiten poner a disposición materias virtualizadas de acuerdo a cada disciplina, con el fin de proporcionar a los alumnos la adquisición de habilidades o contenidos. Los procesos TPK, TCK y PCK dan cuenta de una variable implícita al analizar las narrativas (cuadro 9).

\section{Variable Interna: Conexión a Internet (VICI)}

Cuadro 9. Conversión del concepto Conexión a Internet en variable

\begin{tabular}{|c|c|c|c|}
\hline \multirow[t]{2}{*}{ Concepto } & \multirow[t]{2}{*}{ Indicador } & \multicolumn{2}{|l|}{ Variables } \\
\hline & & Variable & Definición operacional \\
\hline Conexión a internet & $\begin{array}{l}\text { Sistema de enlace } \\
\text { a dispositivos }\end{array}$ & $\begin{array}{l}\text { Proveedores } \\
\text { Banda ancha } \\
\text { Acceso }\end{array}$ & $\begin{array}{l}\text { Navegar. } \\
\text { Visualizar. } \\
\text { Servicios. }\end{array}$ \\
\hline
\end{tabular}

Fuente: Definición: Reka (2002).

Di Gropello (2020) refiere que varios países trabajan proyectos de apoyo a educación en línea o virtual. Entre ellos Uruguay, del que se afirma estaba muy bien preparado para la enseñanza online porque dedicó muchos años a garantizar la conectividad. Los opinantes refieren lo siguiente:

En Uruguay no se sabe cuántos alumnos tienen conexión a Internet, existe un proyecto de nodos wifi que puede dar servicio.

Mientras tanto, en Colombia consideran:

Que las clase virtuales no son igual que la educación presencial, por ello piden que se les regrese el pago de matrícula. Además, hay un cuestionamiento sobre si de verdad todos alumnos cuentan con pc, impresora y conexión a Internet.

País del que también se afirma que se ha invertido en valiosos portales educativos que se han venido desarrollando desde hace tiempo.

En Paraguay, se dice:

Que al estrés se van a sumar las clases mediocres en línea, que muchos no la siguen por falta de recursos que poyen.

En Costa Rica, se dice:

El canal 13 lleva la escuela y el colegio a casa.

\section{Diálo Dos}


En Brasil, se dice que:

si un estudiante en educación pública no tiene clases, no pasa nada, pero si un estudiante asiste a una escuela privada y lo ven tomando clases a distancia, esto sí pone a pensar. Además la mayoría de estudiantes no tienen clase en modo remoto, y no hay fecha de normalización.

En México se dice:

Virtualizar la escuela es parte del proceso de contención social.

Se ha invertido mucho esfuerzo, y por muchos años, en el desarrollo de una televisión educativa multigrado. Entonces ahora le está sacando provecho a este programa, en particular para garantizar equidad. La Telesecundaria, creada en 1968, ha podido acercar la educación a casi un 1.5 millones de estudiantes, llega a las áreas rurales a través de la televisión.

En chile se dice:

la condición de medios y conexión a Internet para impartir clases a distancia, son varias.

El país le está sacando provecho al desarrollo de la evaluación online. Se está usando tanto el programa Aprendo en Línea, una plataforma con recursos digitales para el autoaprendizaje en casa y en familia, así como Aptus, orientado a los centros educativos y que incluye desde software educativo hasta capacitaciones para docentes y evaluaciones para los alumnos.

En El Salvador y Perú se dice:

El Salvador usa el Canal 10 y plataformas adaptadas.

En Perú existe falta de Internet para los alumnos de escasos recursos para realizar clase en línea.

El aula virtual es costosa, importa el papel de padres de familia para ayudar en las clases virtuales, man-

tener el distanciamiento social y procurar las medidas de higiene en el colegio.

En suma, la preparación del proceso educativo virtual es particularmente afectada por la disminución de la banda ancha en algunos países durante el mes de marzo y abril 2020, de acuerdo con Katz, Jung y Callorda (2020), principalmente en Chile (-3\%) y Ecuador (-19.6\%), combinado esto con un incremento de la latencia de la misma tecnología en Brasil (11.7\%), Chile (19.0\%), Ecuador (11.8\%) y México (7.4\%). El Observatorio CAF (2020) manifiesta que, a pesar de la carencia de banda ancha, la digitalización de los hogares latinoamericanos indica una creciente conectividad y uso de Internet en 2020, que asciende a 78.78\%. Países con penetración mucho menor como Bolivia: 58.34\%. El Salvador: 45.02\%. Honduras: 39.33\%. Adicionalmente, la dicotomía rural/urbana indica un nivel importante de marginalización digital. La brecha digital 
creada por la disminución de velocidad es un obstáculo para descargar contenidos educativos para resolver el asueto escolar. En gran parte de los hogares latinoamericanos el uso de Internet se limita a herramientas de comunicación y redes sociales. En resumen, las variables y los procesos componentes del Orgware Virtual Educativo son centrales para ordenar la cantidad de información generada en el entorno socioeducativo a raíz de la pandemia por el COVID-19. Las variables internas explican la variable externa, mientras que los procesos muestran las condiciones en que funciona.

\section{Resultado}

Con respecto a la pregunta ¿Qué sucede en la escuela virtual en el momento actual, tras casi una década de políticas de integración masiva de tecnologías? Sucede que el Orgware Virtual Educativo de ALyC es un sistema cuya sustantividad le permite relacionase con el entorno, de donde la integración, el aseguramiento y la interaccion le aportan energía y orden por medio de las variables que las trasmiten a los procesos. Para dar respuesta a la pregunta ¿Cómo han contribuido los desarrollos tecnológicos para continuar con el periodo escolar en la virtualidad? La estructura VEOVE-VIP-VIC-VICOD y TPAK revelan el desafío que le representa la perspectiva socioeconómica, la competencia pedagógica digital y la competencia de conexión a Internet, pues la comptencia digital por sí sola no alcanza para llevar a cabo el proceso educativo virtual, como tampoco alcanza la lentidud de la red, fallo ligado estrechamente al factor socieconómico. Finalmente ¿Qué viven, especialmente, quienes se encuentran sin conexión a Internet fuera del contexto escolar? Las narrativas reflejan incetidumbre de las personas con respecto a la modalidad virtual (gráfico 1). 
Gráfico 1. Sistema Orgware Virtual Educativo(SOVE) de ALyC en tiempos de pandemia COVID-19

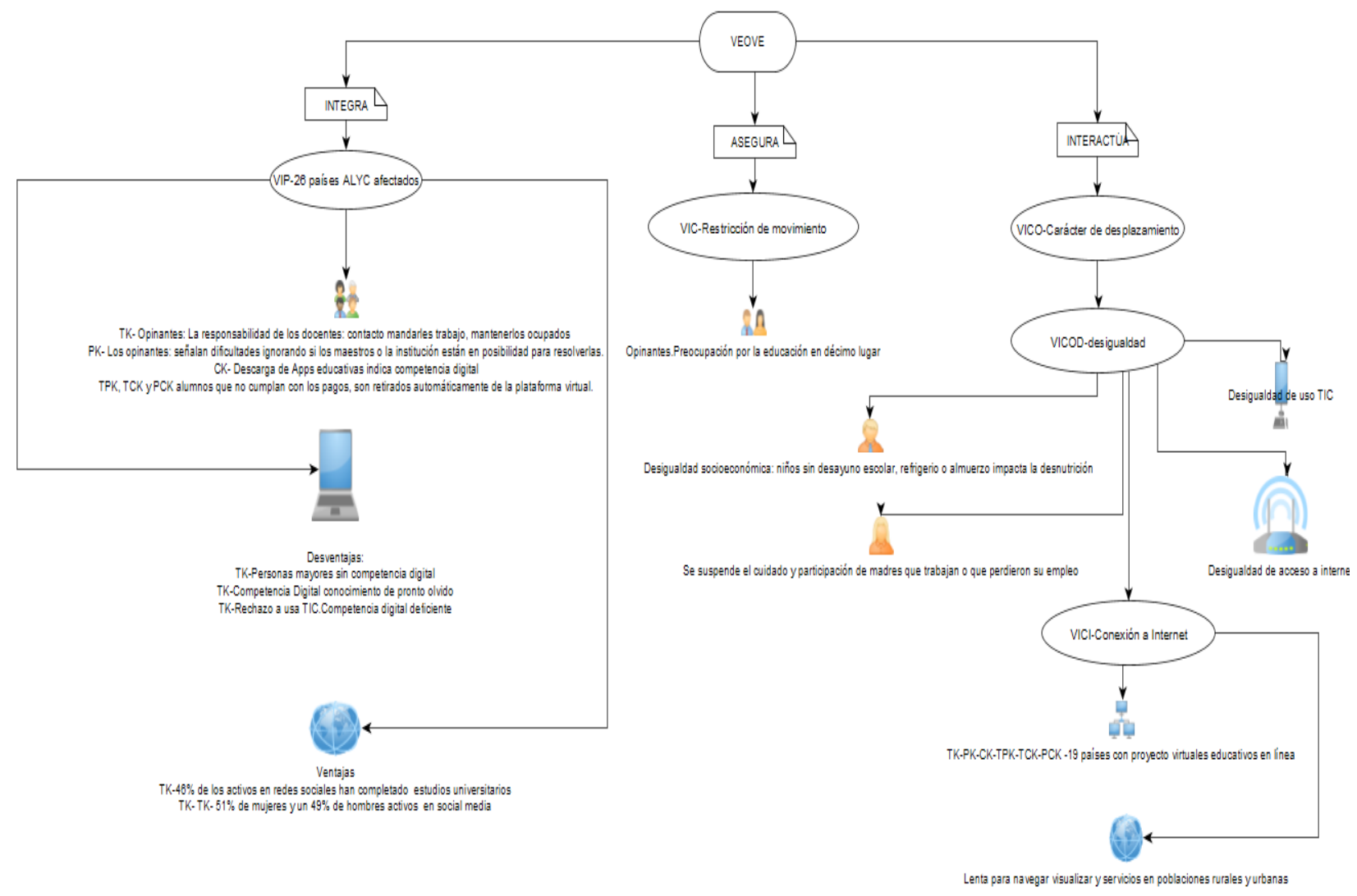

Fuente: Elaboración propia.

\section{Conclusiones}

De acuerdo con lo expuesto, se consiguen las siguientes conclusiones:

Se puede decir que el Orgaware Virtual Educativo (OVE) es un sistema pedagógico tecnológico sustentado en la integración, aseguramiento e interacción. Se integraron 26 países de ALyC que fueron alcanzados por la pandemia provocada por COVID-19, y que además ha facilitado el aseguramiento de la educación durante los primeros meses de la cuarentena. Pero que también ha proporcionado estructuras pedagógicas y tecnológicas para interactuar y hacer frente al carácter restrictivo del desplazamiento. También el OVE se compone de una cultura educativa que se expresa en la forma de asumir la realidad emergente, y se lleva acabo a partir de esquemas mentales de los que al menos se identificaron tres fuentes:

La primera es de orden estático, son las institucionales encargadas de asignar tareas, responsabilidades y distribuir presupuestos para la implementación de proyectos tecnológicos virtuales destinados a atender necesidades educativas durante la emergencia. 
La segunda es la organización funcional a cargo de personas que, al ser sorprendida por la emergencia, presentaron dificultades para operar con principios distintos a los establecidos. Ya no pudieron llevarse a cabo las tareas de la misma forma que las realizaban siempre. Las etapas de trabajo, los desempeños, los materiales y los medios cambiaron de un momento a otro, exigiendo "competencia pedagógica digital". El personal sobre el cual pesa el funcionamiento de la enseñanza se encuentra en desventaja por varios factores (entre ellos la edad) frente al nivel de competencia requerido.

La tercera, cierto es que un sistema tiene como fundamento la simplificación del trabajo, que se traduce en aumentar o mejorar la eficiencia de cada uno de sus procesos. Lo que se convirtió en un problema para el Sistema OVE debido a que se enfrenta a la deficiencia en "competencia pedagógica digital" e "incompetencia en conexión a internet"; la primera, por parte de los docentes, y la segunda por parte de las instituciones. La variable desigualdad socioeconómica incide en la conexión lenta que se encontró en la variable confinamiento como el mayor obstáculo.

Es preciso indagar con detalle acerca del estado que guarda el Sistema OVE en América Latina y el Caribe como apoyo a la educación presencial desde una perspectiva socioeconómica y una perspectiva de competencia pedagógica digital. También habrá que preguntarse ¿Es el SOVE la única opción? Seguramente no, algunos docentes elaboran cuadernos de tareas para alumnos que no tienen acceso a internet, lo entregan por semana casa por casa ¿Se trata de otro Orgware?

\section{Bibliografía}

Almenara, J. C. (2004). Cambios organizativos y administrativos para incorporación de las TIC a la formación. Medidas a adoptar. Edutec. Revista Electrónica de Tecnología Educativa, (18), a044-a044.

Banco Mundial (2020). LAC Equity Lab: Desigualdad - Distribución de Ingresos. https://www. bancomundial.org/es/topic/poverty/lac-equity-lab1/income-inequality/income-distribution

Banco Mundial (2020, Abril). Cómo utilizan la tecnología los países de América Latina durante el cierre de las escuelas a causa de la COVID-19. https://blogs.worldbank.org/es/education/como-utilizan-la-tecnologia-los-paises-de-america-latina-durante-el-cierre-de-las

Borrego, N.; H. Rodríguez; R. Walle; J. Ponce (2008). Educación superior virtual en América Latina: Perspectiva tecnológica-empresarial. Formación Universitaria, 1(5), 3-14.

Brooks, S. K.; R. K. Webster; L. E. Smith; L. Woodland; S. Wessely; N. Greenberg; G. R. Rubin (2020). El impacto psicológico de la cuarentena y cómo reducirla: revisión rápida de la evidencia. The Lancet, 395(10227), 912-920.

Diólo pos año 12 | número 22 | enero-junio 2021 | ISSN 2007-2171 
CEPAL (2020). América Latina y el Caribe ante la pandemia del COVID-19: efectos económicos y sociales. https://repositorio.cepal.org/handle/11362/45337

Charmaz, K. (2013). La teoría fundamentada en el siglo XXI: Aplicaciones para promover estudios sobre la justicia social. En Denzin, N. K.; Y. S. Lincoln (comps.). Estrategias de investigación cualitativa, Vol. III. Gedisa, 270-325.

Delgado, K. E. (2020). Educación inclusiva durante la emergencia: acciones en América Latina. CienciAmérica, 9(2), 154-165. http://cienciamerica.uti.edu.ec/openjournal/index.php/uti/ article/view/302

Di Gropello, E. (2020) 4 Países de América Latina que lograron aplicar estrategias exitosas de educación a distanciaante la pandemia. http://www.bbc.com/mundo/amp/noticias-americalatina-523375867

Dobrov, G. M. (1979). La tecnología en cuanto organización. Revista Internacional de Ciencias Sociales, (4), 635.

Elogia, I. A. B. (2019). IV Estudio Anual de Redes Sociales 2019. https://blog.elogia.net/estudioanual-redes-sociales-2019-iab-elogia

García, C. M.; D. R. Burgos; P. Murillo; J. F. Jáspez (2019). Aprender con tecnologías para enseñar con tecnologías en República Dominicana. El programa República Digital Educación. Revista Iberoamericana de Educación, 79(1), 115-134. https://rieoei.org/RIE/issue/view/283

González, B.; J. Regué (21 de marzo de 2020). Qué se puede y qué no se puede hacer en un confinamiento. El Periódico. https://www.elperiodico.com/es/sociedad/20200321/que-puedehacer-confinamiento-catalunya-coronavirus-7889319

Gutiérrez-Menez, E. (2015). Heteronormatividad, estereotipos y actitudes relacionados al género: Análisis comparativo de materiales didácticos de apoyo para la comprensión lectora de ELE en Suecia. Tesis de maestría. Suecia: Universidad de Linnaeus. https://www.diva-portal.org/ smash/record.jsf?pid=diva2\%3A900446\&dswid=9309

Internet World Stats (2020). Internet World Stats. Usage and Population Statistics. https://www. internetworldstats.com/stats2.htm

Katz, R.; J. Jung; F. Callorda (2020). El estado de la digitalización de América Latina frente a la pandemia del COVID-19. https://centrolatam.digital/article/el-estado-de-la-digitalizacionde-america-latina-frente-a-la-pandemia-de-la-covid-19/

LLoyd, M. (2020). Desigualdades educativas y la brecha digital en tiempos de COVID-19. http://132.248.192.241:8080/jspui/bitstream/IISUE UNAM/546/1/LloydM 2020 Desigualdades educativas.pdf

Lugo, M. T.; V. Ithurburu (2019). Políticas digitales en América Latina. Tecnologías para fortalecer la educación de calidad. Revista Iberoamericana de Educación, 79(1), 11-31.

Melgar, A. M. K.; J. Paredes-Labra; M. D. Reynes (2019). Acontecimientos del Plan Ceibal. Una compleja trama de mediaciones soportando la apuesta inclusiva. Revista lberoamericana de Educación, 79(1), 155-174. 
Mishra, P.; M. J. Koehler (2006). Technological Pedagogical Content Knowledge: A Framework for Teacher Knowledge. Teachers College Record, 108(6), 1017-1054.

Moreno, M. (2019). Las redes sociales más usadas en España en 2019. https://www.trecebits. com/2019/08/01/conoce-cuales-son-las-redes-sociales-mas-utilizadas-en-latinoamerica/

Observatorio CAF (2020). El estado de la digitalización de América Latina frente a la pandemia del COVID-19. Caracas: CAF. https://scioteca.caf.com/handle/123456789/1540

Observatorio COVID-19 BID (2020). ¿De qué está hablando la ciudadanía durante la pandemia COVID-19? https://covid19-civiclytics.citibeats.com/

Real Academia Española (2020). Crisis del COVID-19: apuntes sobre pandemia en la lengua española. https://www.rae.es/noticias/crisis-del-covid-19-apuntes-sobre-pandemia-en-la-lenguaespanola

Reka, A. (2002). Barabási. Statistical Mechanics of Complex Networks. Rev. Mod. Phys, (74), 47-97.

Rivoir, A. L. (2019). Desigualdades digitales y el modelo 1 a 1 como solución. El caso de One Laptop Per Child Perú (2007-2012). Revista Iberoamericana de Educación, 79(1), 33-52.

Rosselli, D. (2020). Epidemiología de las pandemias. Medicina, 42(2). Colombia: Academina Nacional de Medicina.

Soneira, A. J. (2006). La teoría fundamentada en los datos (grounded theory) de Glaser y Strauss. En Vasilachis, I. (coord). Estrategias de investigación cualitativa. Gedisa, 153-173.

Sunkel, G.; H. Ullmann (2019). Las personas mayores de América Latina en la era digital: superación de la brecha digital. Revista CEPAL, (127). Chile: CEPAL.

Urresta Enríquez, A. S. (2017). Vejez, confinamiento y cuerpo: experiencias desde la práctica artística (Bachelor's thesis, PUCE). 